\title{
Morin, Baudrillard e a metáfora do holograma
}

FranciscoE. M enezesM artins

Jornalista, Doutor em Ciências da Comunicação pela Universidade Complutense de Madri e professor da FAMECOS / PUCRS.
Não estamos mais no drama da alienação, estamos no êxtase da comunicação.

Jean Baudrillard

ATÉ QUE o homem tenha a consciência de que quanto maisnoção dahumanidadeelepossui, menoshumano elesetorna, estaseráahistória de um planeta que ficou doente junto com a loucuraracional deseushabitantes racionais. As múltiplas cenas de destruição fizeram contra-ponto ao natural, ao local e ao global. Hoje, em palavras de Edgar Morin: "Não apenas cada parte do mundo faz cada vez maispartedomundo, maso mundoenquanto todo está cada vez mais presente em cada uma de suas partes. Isso se verifica não só para as nações e os povos, mas também para os indivíduos. Da mesma forma que cada ponto do holograma contém a informação do todo de que faz parte, doravante cada indivíduo também recebe ou consome as informações e as substâncias vindas de todo o universo". ${ }^{1}$

M orin utiliza a metáfora do holograma para dimensionar a globalização desde a circularidade dos signos, da mesma forma que Jean Baudrillard autiliza para os Estados Unidos: "A América é um gigantesco holograma, no sentido em que a informação total está contida em cada um dos elementos. Tome-se o mais humilde ponto do deserto, não importa que rua de uma cidade do Centro-Oeste, umparquedeestacionamento, uma mansão californiana, um Burgerking ou um Studebaker, e tem-se toda a A mérica, ao Sul, ao Norte, a leste, quanto a Oeste". 2

Em tempos de explosões virais, de metástasedesignos, omundoéumholograma culturalmente norte-americano, onde cada partecontém as informações sobreseu modo devida.

Uma garrafa de Coca-Cola na antiga União Soviética, durante a Perestroyka , ou na China pós-comunista tinha sabor deliberdade, deliberdadedeconsumo. A osentiremse livres e fazerem algumas opções, as pessoas buscaram a repetição da sensação de uma liberdade simulada "made in USA", 
através do símbolo "coke", que poderia ser definido como uma forma de 'diplomacia líquida'. Neste sentido, o M CD onald's, por exemplo, seria uma embaixada virtual desua utopia realizada, e espal hada pelo mundo como nexo com a intimidade e a familiaridade.

Por cima das cidades, dos países, das culturas regionalistas enacionalistas, nascea consciência de uma intimidade virtual e de umaalteridadeinumana. Umaalteridadecom o que está além dos horizontes anteriores. Estenascimento não implica na mortedo que havia antes, mas em uma mudança na sua perspectiva. Tentáculosespectradosdahiperrealidade em territórios previamente mapeados.

Já em 1962, Morin adiantava alguns conceitos que seriam ampliados em TerraPátria, como a dualidade do sentimento em relação à pátria: "Figura materna (a MãePátria, a quem devemos amor) e paterna (o Estado, a quem devemos obediência)". ${ }^{3}$ Assim, ao longo da história, a aliança PátriaProgresso seconsolida como solução defuturo, apoiada na fécientífica, tecnicista eindustrial. N o período quesucedea Segunda Guerra M undial os caminhos das esperanças progressistas ganham força com o cenário mundial estabelecido. $O$ encantamento cultural é abalado em 1968 e o econômico em 1973.

A Terra dá sinais de estar doente. As respostas totalizantes perdem o sentido e se falaem crisedeorientação. O Muro deBerlim jánão épretexto parafuncionar como o muro das lamentações. Pensar o futuro eresolver o presente são tentativas de buscar respostas. “La realité est cela même qu'on rêve(...) est vraimant la conclusion dema réflexion sur le principe de realité". ${ }^{4}$ Estas idéias de Morin estão esboçadas no livro Le V if Du Sujet e também sugerem, sob a ótica da atualidade, os nebulosos limites da fé no progresso e da realidade do progresso.

Como os acontecimentos se interrelacionam, seus efeitossão sentidospor todas as partes, em maior ou menor grau. A polêmica lei anti-tabaco do presidente dos Estados Unidos, Bill Clinton, que pretende col ocar o cigarro na categoria de 'droga proibida', ainda que seja com finalidades morais e eleitorais, acaba por atingir a economia de vários países. As notícias deste tipo funcionam como aterrorizante/ tranquilizantesocial, na medida em quecolocam a humanidade no lugar de refém do estar informado a respeito do mundo. Circunstâncias da globalização: a juventude da América de maneiraartificial torna-senatural (semál cool esem tabaco). Hipocrisia desdeWashington, já que desde Los Angeles e Hollywood, as imagens da juventude americana lançadas nas redes se perdem na fumaça dos cigarros das estrelas e na embriaguez dos mitos do cinema e da música.

Nestecaso sepodepensar queosjovens americanos são privados desua própria imagem. Desprovidos dos rituais tribais que, no entanto, formam sua identidadeaos ol hos do mundo mediatizado. Também se pode pensar que as imagens não possuem identidade para circular na órbita das redes comunicacionais. Elas não passam por alfândegas enão necessitam apresentar passaportepara entrar em territórios, como as pessoas. A s barreiras físicas não existem para as imagens, uma vez em velocidadecentrífuga, elas já não têm referência no real. Os jovens americanos "em órbita" não guardam referência com a ficção, porque neste caso, a ficção é a simulação desaúdemoral na montagem teatral da Casa Branca.

Em relação à integração sócio-cultural, Morin afirma que: "Tudo se passa como se umaprodigiosaproliferaçãodemitos, deritos, demagia, parasitassecomoumaherao edifício social já muito complexo, mas tudo se passa também como seela constituísse um cimento integrador que penetrasse em todas as suas fendas". ${ }^{5}$ Os rituais permanecem vivos no simulacro, ainda que sejam rituais de uma dissimulação da real idade social em cena. A complexidade da realidadeglobal influencia no devir do indivíduo edo mundo. As partes eo todo mantêm suas dependências no olhar paradoxal. 


\section{Em torno às utopias}

Para Morin, estamos “. . . diante do paradoxo inédito no qual o realismo setorna utópico, e no qual o possível é impossível. Mas esse paradoxo nos diz também que há uma utopia realista, e que há um impossível possível. O princípio da incerteza da realidade é uma brecha tanto no realismo como no impossível.". ${ }^{6}$ Essa complexidade das incertezas da corrida civilizatória traz consigo a certeza de que a realidade e a utopia são as duas faces de uma moeda que ainda gira no ar, à espera da sorte do seu destino.

Juremir Machado da Silva conta que Jean Baudrillard tem uma definição radical, como não poderia deixar de ser, sobre a utopia. Segundo o pensador francês: “Não há nada mais conservador que a utopia, porque jamais redimensiona sua perspectiva". Este ponto devista complementa os próprios conceitos que Baudrillard criou a respeito dos EstadosUnidos, a partir dasidéias derealidade, hiper-realidade, simulacro e utopia realizada “. A Américanão éum sonho nem uma realidade; éumahiper-realidade. É uma hiper-realidade porqueéuma utopia quefoi vividacomo realizada. Tudo aqui éreal, pragmático, e tudo nos deixa sonhadores. É possível que a verdade da A mérica só possa aparecer a um europeu, pois que só este encontra aqui o simulacro perfeito, o da imanência e da transcrição material de todos osvalores.". 7 A fé nareligião do "way of life" como solução aos problemas daquele país e, conseqüentemente, como solução aos problemas da pátria global, por uma questão da lógica do caráter messiânico das seitas protestantes da N oval Inglaterra, no período pósindependência,jamaisfoi redimensionada. $O$ sonho foi realizado e a real idade é sonhada.

Realidadeesonho americano geradores da hiper-realidade. Para os demais países não há vacina contra este vírus da era dos simulacros. No interior dos Estados Unidos, Baudrillard afirma que: “O holograma está próximo do fantasma, é um sonho tridimensional epode-seingressar nelecomo um sonho". 8
A Europadaglobal ização estáfragmentada em nacionalismos. A perspectiva comunitária pós-M aastricht não encontra a atmosfera ideal para propagar-se. Desenvolvimento comum era a nova utopia do velho continente. No devir da modernidade estaria o resultado das razões nacionais ampliadas a outros países. A postura cética do Reino Unido, a divisão deopiniões daFrança ea certeza dalocomotiva germânica geraram incertezas nas demais nações européias. Europaem distintas velocidades. "A democracia modernaé o produto de uma história incerta, que comporta avançoserecuos, naqual emergiram, se afirmaram e se desenvolveram seus princípios". ${ }^{9}$

$\mathrm{N}$ a era das democracias há consensose conflitos. Sua marginalidade é, hoje, uma ausência de vestígios. As cenas do social multiplicadas simultâneamente através das notícias aceleram a sensação de vertigem. $O$ presente perpétuo parece instaurar-se: sem memóriaesem devir. "Osindivíduos só pensam no dia de hoje, consomem o presente, deixam-se fascinar por mil futilidades, tagarelam sem jamais secompreender natorrede babel das bugigangas". ${ }^{10}$

A conexão coma atualidadeéuma neurose social. Vinte e quatro horas por dia as tecnologias da comunicação sustentam as órbitasdossignos. O globoemrede. A história universal de cada dia, em 15 minutos. Nas imagens, referências do presente. Sempre o hoje sem contexto. Uma alucinante sucessão de "hojes". A pretensão de construir realidades simbólicas ou de agendar o pensamento das pessoas são visões teóricas sobre espectros do "hoje", que, no entanto, jamais viveparaviver seu "amanhã". A final, ele é uma lucrativa corrida olímpica de 100 metros. Sem respirar e sem pensar, apenas correr.

Quando o terrorismo é uma estratégia comunicacional, surgem milhões de reféns portadoresdaSíndromedeEstocolmo. Quando o mundo é global, na esfera política: " A manipulação éuma tecnologia desuave violênciapelachantagem.". ${ }^{11}$ Todossomos reféns do "hoje", na mesma forma das massas. "O 
único ato transpolítico é o terrorismo, o que revela nossa miséria transpolítica etira dela conseqüências extremas. E isso, infelizmente para nossos espíritos críticos, de qualquer lado que seja. Não há mensagem na tomada de, elanãotem sentidonem eficiênciapolítica; é um acontecimento sem conseqüências (ele desemboca sempre num dead end): mas os própriosacontecimentospolíticosofereceriam outra coisa além de uma falsa continuidade? É asolução dacontinuidadequeéinteressante. Outrora ela atuava como revolução, hoje ela só consegue chegar a efeitos especiais. E o próprio terrorismo é apenas um gigantesco efeito especial". ${ }^{12}$

A noção do universo é fragmentada e simultânea. Não se questiona se há algum sentido. Se vive com pressa. A publicidade nos seduz à montagem desuper-lares, o nãosocial com conforto e tecnologia. A pressa é pretexto da superficialidade e se manifesta em todos os pontos das redes e das massas. As notícias surgem e se auto-consomem, segundo a lógica consenso/ conflito. O ritmo acelerado reduz a possibilidade de reflexão. As imagens do mundo nos são familiares e nem sabemos o motivo. Elas tapam o vazio dos imaginários ao se colocarem como a alteridade da humanidade.

A consciênciaecológicaéencarnação da natureza desaparecida do mapa e simulada no devir deste planeta, eo racismo, dissimulado pel os que o praticam, indicam os sintomas da velocidade. "Enfim, não esqueçamos que o que faz a originalidade mesma da era planetária do séculoXX, a constituição deum espaço-tempo planetarizado complexo no qual todas as sociedades, arrastadas num mesmo tempo, vivem neletempos diferentes - tempoarcaico, temporural, tempoindustrial, tempo pós-industrial, etc. Tudo isso devenos levar a romper com a idéia de que doravante é preciso alinhar todas as sociedades com base no tempo mais rápido, o tempo cronometrado, o tempo ocidental. Deve nos levar a viver a complementariedadedostempos diferentes, a conter a invasão do tempo cronometrado, a desacelerar o tempo ocidental". ${ }^{13}$
N a troca do espaço pelo tempo, a noção do mundo à alta velocidade dá a impressão deque sobram imagens e de que fal tam imaginários. A previsibilidade do mundo mediatizado é a rotina das rupturas nunca surpreendentes. A destruição da Floresta A mazônicaé, para um europeu, um atentado ao seu oxigênio. Mas também é a máscara caída do progresso. Resta culpar os "estadounidenses"(expressão que exclui Canadá e México da generalização em norte-americanos, quando se quer especificar os Estados Unidos), eo fator terceiro-mundo. A ecologia abrangebaleiasebactérias. A vacinada mídia eliminaasbactérias (ecologiaforçada) efortaleceas baleias ( ecologia das vítimas). Primeiro caso de consciência ecológica: arrependimento e culpa.

Umaveztransparente, aecologiaseleciona os seres. A miséria e a fome não são ecológicas. Segundo caso de consciência ecológica: o homem destrói a Terra. Uma vez globalizada, a responsabilidade é dos sujeitos. A ecologia passa a ser sujeito. Terceiro caso de consciência ecológica: fusão entre sujeito e objeto, homem e natureza.

Segundo Baudrillard: “El peligro absoluto estribaen queen lainteractividad erigida en sistema total decomunicación, el otro deja deexistir, no hay más quesujeto, y dentro de poco ya sólo sujetos sin objetos. No hay nada peor que un sujeto sin objeto. Actualmente, todos nuestros problemas de civilización surgen deahí; ya no del excesso dealienación, sino de una desaparición de la alienación en benefício de una transparência máxima de los sujetos de unos respecto a otros. . . . La balanza, de la que tanto se habla en ecología (out of balance), no se refiere tanto a la de los recursos edelos gastos planetários como ala, metafísica, del sujeto y del objeto. Pero esta balanza metafísica sujeto/ objeto está siendo rota en benefício del sujeto, pertrechado de todas las tecnologías de comunicación avanzada, en el horizonte de las cuales el objeto ha desaparecido". ${ }^{14}$

Na perda do objeto, a ecologia somos todos nós: atores da nostal gia, da consciência ecológica e da emancipação do sujeito. Ver a 
natureza como matéria-prima da qualidade total edas emissões-zero, seria a mesma perspectiva do que a vê como o santuário do paradigma perdido. Virtudes ecológicas proliferadas ao mundo. Desenvolvimento com proteção e proteção do desenvolvimento: interface com o mesmo paradigma.

Em questões de racismo e xenofobia, a globalização desumaniza-se e os vel hos problemas econômicos aliados ao "sentir nacionalista" voltam à tona. Desde o final da segunda guerra mundial, há um fortalecimento dos nacional ismos. $\mathrm{N}$ a era das democracias virtuais, as bandeiras e as economias entram em conflito com as massas. Os imigrantes africanos, asiáticos e latino-americanos ao chegar na Europa da União Européia colocam-senamira dos controles. A sensação de estarem sendo invadidos pelo mundo é vivida pelos indivíduos do velho-continente. O bumerangue, enfim voltou. No momento em que Cristóvão Colombo e sua tripulação revelaram ao mundo o oeste de sua utopia, este dia estava marcado no calendário do progresso dahumanidade. A data: quandoas redes pudessem levar as informações do holograma a cada uma de suas partes. A eraplanetária éa história de uma aceleração em direção ao sonho do homem. O sonho de Colombo erao mesmo dosimigrantes: aesperança emumfuturo abstrato eacertezadeum presente sem respostas foram o combustível da modernidade.

Em algumas cidades européias, como Paris ou A msterdã, se tem a impressão quea ONU enviou representantes de cada país do mundo para formar etnicamente cada parte do holograma. As mesmas tribos do Harlem, em Nova Iorque, caminham pelas ruas de Londres. As pessoas se parecem. As músicas separecem. A aceleração sígnica éa do simulacro. O Planet Hollywood de Barcelona é uma clonagem do de Honolulu. Os negros da MTV são embranquecidos e purificados de sua radicalidade. Os extremos da circularidadesão asformaspuras. Osbrancos daMTV são os verdadeiros negros. Dissimulação deracismo virtual. A harmoniara-cial é um grupo sueco cantanto hip-hop, um
Michael Jackson, negro/ branco, ou uma Madonna, Branca/ negra.

Ecologia e racismo são partes do holograma e mantêm a informação sobre o todo. Em suas imagens, vestígios do crime perfeito deBaudrillard: "Laimagen no puede imaginar lo real, ya que ella misma lo es. Ya no puede soñarlo, ya que ella es su realidad virtual. Escomosi lascosashubieran engollido su espejo y se hubieran convertido en transparentes para sí mismas, enteramente pre sentes para sí mismas, a plena luz, em tiempo real, en una transcripción despiadada. En lugar de estar ausentes de sí mismas, en la ilusión, se ven obligadas a inscribir-se en los millares de pantallas de cuyo horizonte no sólo ha desaparecido lo real, sino también la imagen. La imagen ha sido expulsada de la realidad. Sólo la tecnología sigue tal vez uniendo los fragmentos dispersos de lo real.". ${ }^{15}$ A socialidade na aurora do ciberespaço passapelo inumano, pelo objeto como paradigma perdido. As imagens dos Jogos Olímpicos ou da MTV não possuem ilusão. Elas são exatamente o contrário: simulacro.

Desacelerar o mundo, desafia Morin, enquanto Baudrillard suspeita queo mundo revela seu segredo quando se esconde atrás de suas próprias aparências. A mbos buscam um mundo sem vestígios. Morin reflexiona que: "precisamos tomar consciência dessa corrida louca para onde nos leva o devir que tem cada vez menos a feição do progresso, ou queseria a faceoculta do progresso.... Tratase portanto de frear o avanço técni co sobreas culturas, a civilização, a natureza, que ameaça tanto as culturas como a civilização e a natureza. Trata-sedediminuir a marcha para evitar ou uma explosão ou uma implosão. Trata-se de desacelerar para poder regular, controlar e preparar a mutação. A sobrevivência exige revolucionar o devir. Precisamos chegar a um outro futuro. Essa é que deveser a tomada deconsciência decisiva do novo milênio". ${ }^{16}$

Consciência do devir em uma consciência depátria planetária, deresponsabilidades e abusos, de níveis de desenvolvimento e progresso. Mas, também, consciência de que 
nas partes do holograma global estão os sintomas da virulência dos signos. Há três anos do início do próximo milênio, o culto às imagenséaimagem daglobal ização. A oserem a falta do real, e da ilusão, as imagens se convertem no simulacro perfeito da metáfora do holograma e de um devir hiper-real .

\section{Notas Bibliográficas}

1 MORIN, Edgar, Terra-Pátria, Porto Alegre, Sulina, 1995, p. 35.

2 BAUDRILLARD, Jean, A mérica, Rio de Janeiro, Rocco, 1986, p. 27.

3 MORIN, Edgar, Cultura de massas no século XX - 0 espírito do tempo. Rio de Janeiro, Forense, p. 17.

4 MORIN, Edgar, Le Vif du Sujet, Paris, Éditions du Seuil, 1969, p. 115.

5 MORIN, Edgar, 0 Paradigma Perdido - a natureza do homem, Lisboa, Europa-América, p. 162.

6 MORIN, Edgar, Terra-Pátria, op. cit, p. 140.

7 BAUDRILLARD, Jean, A mérica, op.cit., p. 26.

8 BAUDRILLARD, Jean, A mérica, op.cit,, p. 27.

9 MORIN, Edgar, Terra-Pátria, op.cit, p. 118.

10 MORIN, Edgar, Terra-Pátria, op.cit., p. 89.

11 BAUDRILLARD, Jean, As estratégias fatais, Rio de Janeiro, Rocco, 1996, p. 37.

12 BAUDRILLARD, Jean, As estratégias fatais, op.cit., p. 37.

13 MORIN, Edgar, 1995, Terra-Pátria, op.cit,, p. 155

14 BAUDRILLARD, Jean, La ilusión del fin - la huelga de los acontecimientos, Barcelona, Anagrama, 1993, p. 124.

15 BAUDRILLARD, Jean, El Crimen Perfecto, Barcelona, Anagrama, 1996, p. 15.
16 MORIN, Edgar, Terra-Pátria, op. cit, p. 100.

a

